\title{
SNM Practice Guideline for Lung Scintigraphy $4.0^{*}$
}

\author{
J. Anthony Parker ${ }^{1}$, R. Edward Coleman ${ }^{2}$, Erin Grady ${ }^{3}$, Henry D. Royal ${ }^{4}$, Barry A. Siegel ${ }^{4}$, Michael G. Stabin ${ }^{5}$, \\ H. Dirk Sostman ${ }^{6}$, and Andrew J.W. Hilson ${ }^{7}$ \\ ${ }^{1}$ Beth Israel Deaconess Medical Center, Boston, Massachusetts, ${ }^{2}$ Duke University Medical Center, Durham, North Carolina; ${ }^{3}$ Loyola \\ University Medical Center, Maywood, Illinois; ${ }^{4}$ Mallinckrodt Institute of Radiology, St. Louis, Missouri; ${ }^{5}$ Vanderbilt University, \\ Nashville, Tennessee; ${ }^{6}$ New York Hospital-Cornell Medical Center, New York, New York; and ${ }^{7}$ Royal Free Hospital, London, England
}

\section{PREAMBLE}

The Society of Nuclear Medicine (SNM) is an international scientific and professional organization founded in 1954 to promote the science, technology, and practical application of nuclear medicine. Its 16,000 members are physicians, technologists, and scientists specializing in the research and practice of nuclear medicine. In addition to publishing journals, newsletters, and books, the SNM also sponsors international meetings and workshops designed to increase the competencies of nuclear medicine practitioners and to promote new advances in the science of nuclear medicine.

The SNM will periodically define new practice guidelines for nuclear medicine practice to help advance the science of nuclear medicine and to improve the quality of service to patients throughout the United States. Existing practice guidelines will be reviewed for revision or renewal, as appropriate, on their fifth anniversary or sooner, if indicated.

Each practice guideline, representing a policy statement by the SNM, has undergone a thorough consensus process in which it has been subjected to extensive review, requiring the approval of the Committee on Guidelines and SNM Board of Directors. The SNM recognizes that the safe and effective use of diagnostic nuclear medicine imaging requires specific training, skills, and techniques, as described in each document. Reproduction or modification of the published practice guideline by those entities not providing these services is not authorized.

These guidelines are an educational tool designed to assist practitioners in providing appropriate care for patients.

\footnotetext{
Received Nov. 30, 2011; revision accepted Dec. 8, 2011.

For correspondence or reprints contact: J. Anthony Parker, Beth Israel Deaconess Medical Center, 330 Brookline Ave., Boston, MA 02215.

E-mail: j.a.parker@ieee.org

*NOTE: YOU CAN ACCESS THIS ACTIVITY THROUGH THE SNM WEB SITE

(http://www.snm.org/guidelines).

Published online Jan. 26, 2012.

COPYRIGHT @ 2012 by the Society of Nuclear Medicine, Inc.

DOI: $10.2967 /$ jnmt.111.101386
}

They are not inflexible rules or requirements of practice and are not intended, nor should they be used, to establish a legal standard of care. For these reasons and those set forth below, the SNM cautions against the use of these guidelines in litigation in which the clinical decisions of a practitioner are called into question.

The ultimate judgment regarding the propriety of any specific procedure or course of action must be made by the physician or medical physicist in light of all the circumstances presented. Thus, there is no implication that an approach differing from the guidelines, standing alone, was below the standard of care. To the contrary, a conscientious practitioner may responsibly adopt a course of action different from that set forth in the guidelines when, in the reasonable judgment of the practitioner, such course of action is indicated by the condition of the patient, limitations of available resources, or advances in knowledge or technology subsequent to publication of the guidelines.

The practice of medicine involves not only the science, but also the art, of dealing with the prevention, diagnosis, alleviation, and treatment of disease. The variety and complexity of human conditions make it impossible to always reach the most appropriate diagnosis or to predict with certainty a particular response to treatment. Therefore, it should be recognized that adherence to these guidelines will not ensure an accurate diagnosis or a successful outcome. All that should be expected is that the practitioner will follow a reasonable course of action based on current knowledge, available resources, and the needs of the patient to deliver effective and safe medical care. The sole purpose of these guidelines is to assist practitioners in achieving this objective.

\section{INTRODUCTION}

This guideline describes the technique of performing and interpreting ventilation and perfusion scintigraphy.

\section{GOALS}

The purpose of this guideline is to assist nuclear medicine practitioners in recommending, performing, interpreting, and reporting the results of ventilation and perfusion lung scintigraphy. 


\section{DEFINITIONS}

Lung scintigraphy is a diagnostic imaging procedure that uses ventilation scintigraphy, perfusion scintigraphy, or both to evaluate cardiovascular and pulmonary disorders. Aerosol ventilation scintigraphy is a diagnostic imaging test that records the bronchopulmonary distribution of an inhaled radioactive aerosol within the lungs. Gas ventilation scintigraphy is a diagnostic imaging test that records the pulmonary distribution of a radioactive gas during breathing. Pulmonary perfusion scintigraphy is a diagnostic imaging test that records the distribution of pulmonary arterial blood flow. Radiographic pulmonary evaluation is a chest radiograph or CT scan used to evaluate the pulmonary parenchyma.

\section{COMMON CLINICAL INDICATIONS}

Indications for lung scintigraphy include, but are not limited to, the following:

\section{A. Most common clinical indication}

The most common clinical indication for lung scintigraphy is to determine the likelihood of pulmonary embolism.

\section{B. Less common clinical indications}

1. Document the degree of resolution of pulmonary embolism.

2. Quantify differential pulmonary function before pulmonary surgery for lung cancer (1-3).

3. Evaluate lung transplants $(4,5)$.

4. Evaluate congenital heart or lung disease such as cardiac shunts, pulmonary arterial stenoses, and arteriovenous fistulae and their treatment (6).

5. Confirm the presence of bronchopleural fistula $(7,8)$.

6. Evaluate chronic pulmonary parenchymal disorders such as cystic fibrosis $(9,10)$.

7. Evaluate the cause of pulmonary hypertension (11).

\section{QUALIFICATIONS AND RESPONSIBILITIES OF PERSONNEL}

Refer to the SNM Guideline for General Imaging.

\section{PROCEDURE/SPECIFICATIONS OF THE EXAMINATION}

\section{A. Nuclear medicine study request}

1. In women of childbearing age, pregnancy and lactation status should be noted and the procedure performed in a manner to minimize radiation exposure.

2. The referring physician's estimate of the prior probability of pulmonary embolism may be helpful. Use of validated tools such as the Wells (12) score is preferred.
3. Results of D-dimer test, if obtained, should be noted.

4. History of prior deep venous thrombosis or pulmonary embolism should be elicited.

5. Prior lung scintigraphy should be reviewed. Defects from prior pulmonary emboli do not always resolve completely.

6. Pertinent chest radiographic findings include, but are not limited to, consolidation, atelectasis, effusions, masses, cardiomegaly, and decreased pulmonary vasculature. The chest radiograph may be normal in patients with pulmonary embolism.

7. Treatment with anticoagulant or thrombolytic therapy should be noted.

8. Results of tests for deep venous thrombosis, for example, compression ultrasonography, should be noted.

\section{B. Patient preparation and precautions}

1. A standard chest radiograph in both posterior-anterior and lateral projections is preferred. A portable anterior-posterior chest radiograph is acceptable only if the patient cannot tolerate a routine chest radiographic examination. In patients who have no changes in signs or symptoms, a chest radiograph within a few days may be adequate.

2. A CT scan can substitute for the chest radiography.

\section{Radiopharmaceuticals}

${ }^{99 \mathrm{~m} T c}$ has a half-life of $6 \mathrm{~h}$, a photopeak of $140 \mathrm{keV}$, and isomeric transition decay. ${ }^{133} \mathrm{Xe}$ has a half-life of $5.2 \mathrm{~d}$, a photopeak of $81 \mathrm{keV}$, and $\beta$-decay. ${ }^{81 \mathrm{~m}} \mathrm{Kr}$ has a half-life of $13 \mathrm{~s}$, a photopeak of $190 \mathrm{keV}$, and isomeric transition decay.

1. Aerosols

${ }^{99 \mathrm{~m}} \mathrm{Tc}$-diethylenetriaminepentaacetic acid (DTPA) is the most commonly used radiopharmaceutical. ${ }^{99 \mathrm{~m}} \mathrm{Tc}$ sulfur colloid is another option and has a slower clearance from the lungs. The usual dispensed

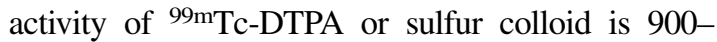
$1,300 \mathrm{MBq}(25-35 \mathrm{mCi})$ in the nebulizer, from which the patient receives approximately 20-40 $\mathrm{MBq}(0.5-1.0 \mathrm{mCi})$ to the lungs. ${ }^{99 \mathrm{~m}} \mathrm{Tc}-$ labeled ultrafine carbon suspension has a more uniform distribution in the lungs than ${ }^{99 \mathrm{~m}} \mathrm{Tc}$ DTPA aerosol but is currently not available in the United States.

Aerosol imaging is usually performed before perfusion imaging because it is more difficult to deliver a larger dose of the ${ }^{99 \mathrm{~m}} \mathrm{Tc}$ aerosol than it is to deliver a larger dose of ${ }^{99 \mathrm{~m}} \mathrm{Tc}$-macroaggregated albumin (MAA). Because both agents are labeled with ${ }^{99 \mathrm{~m}} \mathrm{Tc}$, it is extremely important that the counting rate of the second study is at least 3 to 4 times the counting rate of the first study. 
2. ${ }^{81 \mathrm{~m}} \mathrm{Kr}$

${ }^{81 \mathrm{~m}} \mathrm{Kr}$ is obtained from an ${ }^{81} \mathrm{Rb} /{ }^{81 \mathrm{~m}} \mathrm{Kr}$ generator but is currently not available in the United States. ${ }^{81 \mathrm{~m}} \mathrm{Kr}$ is administered by continuous inhalation of approximately 40-400 MBq (1-10 $\mathrm{mCi})$.

3. ${ }^{133} \mathrm{Xe}$

The usual administered activity of ${ }^{133} \mathrm{Xe}$ is 200-750 MBq (5-20 mCi). The usual dose for children is $10-12 \mathrm{MBq} / \mathrm{kg}(0.3 \mathrm{mCi} / \mathrm{kg})$, with a minimum of $100-120 \mathrm{MBq}(3 \mathrm{mCi})$. The imaging room should provide appropriate exhaust for radioactive gas. Regulations for safe handling of radioactive gas should be followed.

4. Perfusion

Before intravenous administration of the pulmonary perfusion radiopharmaceutical, the patient should be instructed to cough and to take several deep breaths. The patient should be supine during injection or, in the case of a patient with orthopnea, as close to supine as possible.

The radiopharmaceutical used for perfusion imaging is ${ }^{99 m}$ Tc-MAA. The biologic half-life of the MAA in the lungs varies (usually 1.5-3 h).

The usual adult administered activity is 40-150 $\mathrm{MBq}(1-4 \mathrm{mCi})$. The usual pediatric administered activity is $1.11 \mathrm{MBq} / \mathrm{kg}(0.03 \mathrm{mCi} / \mathrm{kg})$, with a minimum of $14.8 \mathrm{MBq} / \mathrm{kg}(0.4 \mathrm{mCi})$ if no ${ }^{99 \mathrm{~m}} \mathrm{Tc}$ ventilation study is performed or $2.59 \mathrm{MBq} / \mathrm{kg}(0.07 \mathrm{mCi} /$ $\mathrm{kg}$ ) if a ${ }^{99 \mathrm{~m}} \mathrm{Tc}$ ventilation study is performed (13).

The number of particles should be in the range of 200,000-700,000. For children, the number of particles should be a function of age (14).

Freshly prepared $99 \mathrm{~m}$ Tc-MAA with reduced numbers of particles should be considered for patients with pulmonary hypertension or right-toleft shunting and for infants and children. In adults, the number may be reduced to 100,000-200,000 particles without altering the quality of the images for detection of perfusion defects. Inhomogeneous distribution of activity may result from a reduction of the number of particles to below 100,000 in adults.

Labeled MAA particles will settle in the vial with time. Vials should be agitated before a dose is withdrawn, and the syringe should be inverted before injection.

\section{Protocol/image acquisition}

\section{Sequence of imaging}

A chest radiograph should be obtained and reviewed before lung scintigraphy. Ventilation scintigraphy using ${ }^{133} \mathrm{Xe}$ is usually performed before perfusion scintigraphy. Alternately, perfusion scintigraphy can be performed first and ventilation scintigraphy omitted if not needed.

The disadvantages of performing perfusion imaging before ventilation imaging with ${ }^{133} \mathrm{Xe}$ are that the perfusion image contributes background activity to the ventilation image, and a decision to perform or not to perform the ventilation study must be made in a timely manner. The advantages of performing perfusion imaging before ventilation imaging with ${ }^{133} \mathrm{Xe}$ are that if the perfusion study is normal or matches the chest radiographic findings, the ventilation study can be omitted, and for single-projection ventilation studies the projection that best shows the defect can be obtained.

Because of the higher energy of the $\gamma$-emissions and the short half-life of ${ }^{81 \mathrm{~m}} \mathrm{Kr}$, images obtained with this gas can be alternated with those obtained with ${ }^{99 m}$ Tc-MAA. When ${ }^{99 m}$ Tc-labeled aerosol imaging is performed before ${ }^{99 \mathrm{~m}} \mathrm{Tc}-\mathrm{MAA}$ perfusion imaging, smaller amounts $(20-40 \mathrm{MBq}$ [0.5-1.0 mCi]) of ${ }^{99 m}$ Tc-labeled aerosol should be administered to the lungs.

2. Processing

There are no processing steps.

3. Aerosol ventilation imaging

The aerosol is administered through a mouthpiece with the nose occluded while the patient is engaging in tidal breathing.

An advantage of aerosol imaging is that images can be obtained in multiple projections or with SPECT to match those obtained for perfusion imaging. It is preferable for the patient to be upright while inhaling the aerosol, but the patient can be supine if necessary. Aerosol ventilation imaging can be performed at the bedside. A disadvantage of aerosol imaging is that aerosol deposition is altered by turbulent flow, and central deposition can result in a suboptimal study.

SPECT can be used to obtain a 3-dimensional evaluation of ventilation and is recommended by some investigators.

4. ${ }^{133} \mathrm{Xe}$ ventilation imaging

An advantage of ${ }^{133} \mathrm{Xe}$ ventilation is that single-breath, wash-in or equilibrium, and washout images can be obtained, thus providing a more complete characterization of ventilation and a more sensitive test for obstructive airway disease. Physiologic information about ventilation can best be obtained from ${ }^{133} \mathrm{Xe}$ imaging.

The imaging room should provide appropriate exhaust for radioactive gas. Regulations for safe handling of radioactive gas should be followed. The patient is positioned upright in front of the scintillation camera. If necessary, the patient can be positioned supine.

The projection that best shows the defects on perfusion scintigraphy is used for the ventilation scintigraphy if performed after perfusion scintigraphy. Otherwise, the posterior projection is generally used. When possible, posterior oblique 
images should be obtained during the washout phase (and during the wash-in phase if continuous imaging is performed during this phase).

If ventilation scintigraphy is performed after perfusion scintigraphy, a ${ }^{99 \mathrm{~m}} \mathrm{Tc}$ background image should be obtained using the ${ }^{133} \mathrm{Xe}$ window. A facemask or mouthpiece (with nose clip) should be connected via a bacterial filter to the xenon delivery system. Single-breath, equilibrium, and washout images are obtained. Equilibrium is obtained by having the patient breathe in a closed xenon delivery system for 3-4 min as tolerated.

5. ${ }^{81 \mathrm{~m}} \mathrm{Kr}$ imaging

The advantage of ${ }^{81 \mathrm{~m}} \mathrm{Kr}$ is that images can be obtained in all views without interference from prior perfusion imaging.

A disadvantage of ${ }^{81 \mathrm{~m}} \mathrm{Kr}$ is that the short half-life of the parent radionuclide, ${ }^{81} \mathrm{Rb}(4.57 \mathrm{~h})$, decreases availability and increases the cost of the generator.

Alternating ${ }^{99 \mathrm{~m}} \mathrm{Tc}-\mathrm{MAA}$ and ${ }^{81 \mathrm{~m}} \mathrm{Kr}$ imaging allows ventilation and perfusion images to be obtained without patient repositioning between paired ${ }^{99 \mathrm{~m}}$ Tc-MAA and ${ }^{81 \mathrm{~m}} \mathrm{Kr}$ views. The patient breathes continuously from the ${ }^{81} \mathrm{Rb} /{ }^{81 \mathrm{~m}} \mathrm{Kr}$ generator. Because of the short half-life of ${ }^{81 \mathrm{~m}} \mathrm{Kr}$, the distribution of radioactivity approximates regional minute ventilation rate. A collimator with low septal penetration at $190 \mathrm{keV}$ should be used. SPECT can be used to obtain a 3-dimensional evaluation of ventilation.

6. Perfusion imaging

After the patient has been told to cough and take several deep breaths, ${ }^{99 \mathrm{~m}}$ Tc-MAA is injected slowly during 3-5 respiratory cycles with the patient supine. A well-flushed indwelling line can be used if venous access is difficult. The tracer should not be administered in the distal port of a SwanGanz catheter or any indwelling line or port that contains a filter-for example, a chemotherapy line.

Imaging is preferably performed with the patient upright to increase chest cavity size and to minimize diaphragmatic motion. If necessary, images can be obtained with the patient in the supine or decubitus position. Planar images should be obtained in multiple projections including anterior, posterior, both posterior oblique, both anterior oblique, and both lateral projections. Either the anterior oblique or the lateral projections can be omitted. It may be possible to obtain only limited views in some patients.

SPECT can be used to obtain a 3-dimensional evaluation of the perfusion and is recommended by some investigators. Imaging of high-blood-flow systemic organs can be used to detect right-to-left shunting. Images of the brain may be obtained to distinguish right-to-left shunting from systemic distribution of radiopharmaceutical components too small to be trapped by capillaries.

7. SPECT/low-dose CT $(15,16)$

Lung scintigraphy for pulmonary embolism may be performed using SPECT/low-dose CT. The low-dose CT portion of the study provides information for attenuation and, compared with a chest radiograph, also provides improved anatomic information.

Ventilation imaging is practical using an agent that has a stable distribution, ${ }^{99 \mathrm{~m}} \mathrm{Tc}$ carbon microparticles, ${ }^{81 \mathrm{~m}} \mathrm{Kr}$, or ${ }^{99 \mathrm{~m}} \mathrm{Tc}$ aerosols. The CT portion of the study should be performed as described in the Guideline for SPECT/CT.

\section{E. Interpretation}

1. Diagnostic criteria (Table 1)

The modified PIOPED criteria were derived from a retrospective analysis of the PIOPED database $(17,18)$. The criteria were prospectively tested and shown to be more accurate than the original PIOPED criteria (19). In an attempt to reduce the number of nondiagnostic studies, the PIOPED II criteria were modified using fewer categories. The performance of the modified PIOPED II criteria was evaluated on the PIOPED II database (20). The modified PIOPED II and PISAPED criteria using information from chest radiograph and perfusion scans have been shown to perform equivalently to those including ventilation scintigraphy, with fewer nondiagnostic studies (21).

2. Gestalt interpretation

The experienced nuclear medicine physician may be able to provide a more accurate interpretation of the ventilation-perfusion study than is provided by the criteria alone; however, the physician's opinion is usually informed by detailed knowledge of the various lung image interpretive criteria given in E.1 (17).

3. Further interpretive considerations (22)

Ventilation-perfusion mismatch can result from any cause of pulmonary arterial blood flow obstruction. Although there is a long differential diagnosis for ventilation-perfusion mismatch, there are few common causes: acute pulmonary embolism, old pulmonary embolism, obstruction of an artery by tumor, and radiation therapy. On perfusion scintigraphy, extrapulmonary activity (which may be seen at the edges of lung images in the thyroid or kidneys) may be the result of right-to-left shunting, free ${ }^{99 \mathrm{~m}} \mathrm{Tc}$-pertechnetate, reduced ${ }^{99 \mathrm{~m}} \mathrm{Tc}$ compounds, or another recent nuclear medicine procedure. An image of the head can be used to differentiate free ${ }^{99 \mathrm{~m}} \mathrm{Tc}$-pertechnetate or reduced ${ }^{99 m}$ Tc compounds from a right-to-left shunting. The stripe sign (activity at the periphery of a per- 
fusion defect) lowers the likelihood that a perfusion defect is due to pulmonary embolism.

4. Interpretation of right-to-left shunt studies

The presence of a right-to-left shunt is identified by activity in systemic vascular beds. An image of the head provides the most accurate method to detect small shunts. Activity due to shunting of ${ }^{99 \mathrm{~m}} \mathrm{Tc}-\mathrm{MAA}$ particles will correspond to brain perfusion, whereas other activity will be seen in the scalp. The fraction of right-to-left shunting can be approximated by comparing the activity in the lungs to the activity in the rest of the body.

5. Interpretation of preoperative lung scintigraphy
Each lung is generally divided into 3 equal rectangular regions of interest on anterior and posterior views: top, middle, and bottom. The activity in the 6 regions of interest is reported for perfusion or for both ventilation and perfusion. An anatomically based description of the perfusion should be provided. Alternative methods of quantification with regions that correspond more closely to pulmonary anatomy are preferred by some experts.

6. Interpretation of posttransplantation lung scintigraphy

In the immediate posttransplantation setting, perfusion imaging documents the patency of the vascu-

TABLE 1

Ventilation, Perfusion, and Radiographic Interpretive Criteria for Pulmonary Embolism

\begin{tabular}{|c|c|c|c|}
\hline PIOPED & Modified PIOPED II & $\begin{array}{c}\text { Perfusion-only modified } \\
\text { PIOPED II }\end{array}$ & $\begin{array}{l}\text { Perfusion-only } \\
\text { PISAPED }\end{array}$ \\
\hline High LR & High LR & PE present & PE present \\
\hline $\begin{array}{l}>2 \text { large mismatched }(\mathrm{V}: \mathrm{Q}) \\
\text { segmental defects }^{\star}\end{array}$ & $\begin{array}{l}\geq 2 \text { large mismatched }(\mathrm{V}: \mathrm{Q}) \\
\text { segmental defects }^{\star}\end{array}$ & $\begin{array}{l}\geq 2 \text { large mismatched } \\
\text { (Q:CXR) segmental } \\
\text { defects }^{*}\end{array}$ & $\begin{array}{l}\geq 1 \text { wedge-shaped } \\
\mathrm{Q} \text { defects }\end{array}$ \\
\hline \multicolumn{4}{|l|}{ Borderline high LR } \\
\hline \multicolumn{4}{|l|}{$\begin{array}{l}2 \text { large mismatched }(\mathrm{V}: \mathrm{Q}) \\
\text { segmental defects }\end{array}$} \\
\hline Intermediate LR & Nondiagnostic & Nondiagnostic & Nondiagnostic \\
\hline $\begin{array}{l}2 \text { moderate or } 1 \text { large mismatched } \\
(\mathrm{V}: \mathrm{Q}) \text { defect* }^{*} \\
\text { Difficult to categorize as high or low }\end{array}$ & All other findings & All other findings & $\begin{array}{l}\text { Cannot classify as } \\
\text { PE-present or } \\
\text { PE-absent }\end{array}$ \\
\hline \multicolumn{4}{|l|}{ Borderline low LR } \\
\hline \multicolumn{4}{|l|}{1 matched $(\mathrm{V}: \mathrm{Q})$ defect, CXR-negative } \\
\hline \multicolumn{4}{|l|}{ Low LR } \\
\hline \multicolumn{4}{|l|}{$\begin{array}{l}\text { Nonsegmental perfusion defects }{ }^{\dagger} \\
Q \text { defect substantially }<\text { CXR defect } \\
\text { Matched }(V: Q) \text { defects, CXR-negative } \\
\text { Any number of small Q defects* }\end{array}$} \\
\hline Normal & Very low LR & PE absent & PE absent \\
\hline \multirow[t]{3}{*}{ No $Q$ defects } & $\begin{array}{l}\text { Nonsegmental }{ }^{\dagger} \\
\text { Q defect }<\text { CXR lesion } \\
\text { 1-3 small segmental } \\
\text { defects } \\
\text { Solitary matched (V:Q:CXR) } \\
\text { defect ( } \leq 1 \text { segment) in mid } \\
\text { or upper lung } \\
\text { Stripe sign }{ }^{\star} \\
\text { Solitary large pleural } \\
\text { effusion§ } \\
\geq 2 \text { matched (V:Q) defects, } \\
\text { regionally normal CXR }\end{array}$ & $\begin{array}{l}\text { Very low probability } \\
\text { Nonsegmental }{ }^{\dagger} \\
\text { Q defect }<\mathrm{CXR}^{\text {lesion }} \\
\text { 1-3 small segmental } \\
\text { defects } \\
\text { Solitary matched (Q:CXR) } \\
\text { defect ( } \leq 1 \text { segment) in } \\
\text { mid or upper lung } \\
\text { Stripe sign }{ }^{\ddagger} \\
\text { Solitary large pleural } \\
\text { effusion } \\
\text { ef }\end{array}$ & $\begin{array}{l}\text { Non-wedge-shaped } \\
\text { Q defect } \\
\text { Contour defect caused } \\
\text { by enlarged heart, } \\
\text { mediastinum, or } \\
\text { diaphragm } \\
\text { Near-normal Q } \\
\text { Normal Q }\end{array}$ \\
\hline & \multicolumn{3}{|l|}{ Normal } \\
\hline & \multicolumn{3}{|l|}{ No $Q$ defects } \\
\hline \multicolumn{4}{|c|}{$\begin{array}{l}{ }^{*} \text { Or equivalent where large segmental defect, }>75 \% \text { of segment, equals } 1 \text { segmental equivalent; moderate defect, } 25 \%-75 \% \text { o } \\
\text { segment, equals } 0.5 \text { segmental equivalent; small defect, }<25 \% \text {, is not counted. } \\
{ }^{\dagger} \text { For example, prominent hilum, cardiomegaly, elevated diaphragm, linear atelectasis, or costophrenic angle effusion with no othe } \\
\text { perfusion defect in either lung and no other radiographic lesion. } \\
{ }^{\ddagger} \text { Peripheral perfusion in a defect (best seen on tangential view). } \\
\text { §Pleural effusion in at least one third of pleural cavity, with no other perfusion defect in either lung. } \\
{ }^{\|} \text {Perfusion defects exactly match shape of CXR. } \\
\mathrm{V}: \mathrm{Q}=\text { ventilation-perfusion; CXR = chest radiograph; PE = pulmonary embolism; LR = likelihood ratio. }\end{array}$} \\
\hline
\end{tabular}


lar anastomoses. In single-lung transplantation, the ratio of right-to-left lung perfusion and the change in ratio correlate with rejection. Analysis of regional changes in ventilation and perfusion may also be useful. Development of matched ventilation perfusion abnormalities consistent with obstructive lung disease often reflects rejection (bronchiolitis obliterans).

7. Sources of error

Perfusion images can show hot spots in the lung if clotting of blood occurs in the syringe during the injection or if the injection is made through an indwelling catheter that is not well flushed.

Ventilation scintigraphy is obtained at a different point in time from perfusion scintigraphy. In the intervening time, there can be changes in ventilation and perfusion. Similarly, ventilation scintigraphy may be obtained with the patient upright, and the radiopharmaceutical for perfusion scintigraphy typically is injected with the patient supine. These changes in position may also affect the comparability of the 2 scintigrams.

Injection of ${ }^{99 \mathrm{~m}} \mathrm{Tc}-\mathrm{MAA}$ through a central line can result in inadequate mixing of activity in the pulmonary artery. This inadequate distribution of activity is especially true if the activity is injected through a pulmonary artery line.

A decubitus or oblique patient position can markedly affect the distribution of ventilation and perfusion. If ventilation scintigraphy or the injection for perfusion scintigraphy is performed with the patient in the decubitus or oblique position, mismatched patterns can result. Accordingly, any nonstandard patient positioning should be recorded and considered during subsequent interpretation.

Activity in the thyroid is often used as an indicator of free ${ }^{99} \mathrm{~m}$ Tc-pertechnetate in the radiopharmaceutical preparation. However, the thyroid is also a high-flow organ and may be visualized in the case of a right-to-left shunt.
8. Issues requiring further clarification

There is considerable literature on SPECT lung scintigraphy, and there is emerging literature on SPECT/low-dose CT lung scintigraphy (23). However, there is currently no information about the comparison of these methods with planar imaging in a multiinstitutional setting (24). The criteria for interpretation of SPECT and SPECT/low-dose CT need to be established. The utility of breathing maneuvers or gating in the context of SPECT and SPECT/low-dose CT needs to be established. The radiation-absorbed dose that provides adequate diagnostic information for use in low-dose CT needs to be established. Finally, the utility of adding ventilation imaging to anatomic and perfusion imaging needs further study $(21,23)$.

\section{F. Interventions}

In patients with acute obstructive lung disease, the use of bronchodilator therapy before lung scintigraphy may decrease ventilatory defects and improve the accuracy of the study. Because perfusion defects often change as acute obstruction resolves, patients are best imaged when bronchospasm has resolved. In patients with congestive heart failure, improved specificity will be obtained if imaging can be delayed until therapy for heart failure has been instituted.

\section{DOCUMENTATION/REPORTING}

\section{A. Goals of a nuclear medicine report}

Refer to the SNM Guideline for General Imaging.

\section{B. Direct communication}

Refer to the SNM Guideline for General Imaging.

\section{Written communication}

Refer to the SNM Guideline for General Imaging.

\section{Contents of the nuclear medicine report}

Refer to the SNM Guideline for General Imaging. 1. Study identification

TABLE 2

Radiation Dosimetry in Adults

\begin{tabular}{|c|c|c|c|c|c|c|c|}
\hline \multirow[b]{2}{*}{ Radiopharmaceutical } & \multicolumn{2}{|c|}{ Administered activity } & \multicolumn{3}{|c|}{ Largest radiation dose } & \multicolumn{2}{|c|}{ Effective dose ${ }^{*}$} \\
\hline & $\mathrm{MBq}$ & $\mathrm{mCi}$ & Organ & $\mathrm{mGy} / \mathrm{MBq}$ & $\mathrm{rad} / \mathrm{mCi}$ & $\overline{\mathrm{mSv}} / \mathrm{MBq}$ & $\mathrm{rem} / \mathrm{mCi}$ \\
\hline${ }^{99 m} \mathrm{Tc}^{-\mathrm{MAA}^{\dagger}}$ & $40-150$ & $1.1-4.1$ & Lung & 0.067 & 0.25 & 0.011 & 0.041 \\
\hline${ }^{99 m} \mathrm{Tc}_{\mathrm{C}} \mathrm{DTPA}^{\ddagger}$ & $20-40$ & $0.54-1.1$ & Bladder & 0.047 & 0.17 & 0.0061 & 0.023 \\
\hline${ }^{133} \mathrm{Xe}^{\S}$ & $200-750$ & $5.4-20$ & Lung & 0.0011 & 0.0041 & 0.00071 & 0.0026 \\
\hline $81 \mathrm{~m} K r \|$ & $40-400$ & $1.1-11$ & Lung & 0.00021 & 0.00078 & 0.000027 & 0.0001 \\
\hline 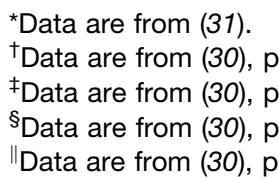 & $\begin{array}{l}224 . \\
218 . \\
345 \text {, rebrea } \\
160 .\end{array}$ & for 5 min. & & & & & \\
\hline
\end{tabular}


TABLE 3

Radiation Dosimetry in Children (5 Years Old)

\begin{tabular}{|c|c|c|c|c|c|c|c|}
\hline \multirow[b]{2}{*}{ Radiopharmaceutical } & \multicolumn{2}{|c|}{ Administered activity } & \multicolumn{3}{|c|}{ Largest radiation dose } & \multicolumn{2}{|c|}{ Effective dose } \\
\hline & $\mathrm{MBq} / \mathrm{kg}$ & $\mathrm{mCi} / \mathrm{kg}$ & Organ & mGy/MBq & $\mathrm{rad} / \mathrm{mCi}$ & $\mathrm{mSv} / \mathrm{MBq}$ & $\mathrm{rem} / \mathrm{mCi}$ \\
\hline 99mTc MAA* & $0.5-2$ & $0.014-0.054$ & Lung & 0.21 & 0.78 & 0.038 & 0.14 \\
\hline${ }^{99 \mathrm{~m}} \mathrm{Tc}_{\mathrm{DTPA}}^{\dagger}$ & $0.4-0.6$ & $0.011-0.016$ & Bladder & 0.12 & 0.44 & 0.020 & 0.074 \\
\hline${ }^{133} \mathrm{Xe}^{\ddagger}$ & $10-12$ & $0.27-0.32$ & Lung & 0.0037 & 0.014 & 0.0027 & 0.010 \\
\hline $81 \mathrm{~m} \mathrm{Kr}^{\S}$ & $0.5-5$ & $0.014-0.14$ & Lung & 0.00068 & 0.0025 & 0.000088 & 0.00033 \\
\hline \multicolumn{8}{|c|}{$\begin{array}{l}{ }^{\star} \text { Data are from }(30) \text {, page } 224 . \\
{ }^{\dagger} \text { Data are from }(30), \text { page } 218 . \\
{ }^{\ddagger} \text { Data are from }(30) \text {, page } 345 \text {, rebreathing for } 5 \mathrm{~min} . \\
\text { §Data are from }(30) \text {, page } 160 .\end{array}$} \\
\hline
\end{tabular}

TABLE 4

99mTc-MAA: Dose Estimates to the Fetus

\begin{tabular}{|c|c|c|c|c|}
\hline \multirow[b]{2}{*}{ Stage of gestation } & \multicolumn{4}{|c|}{ Fetal dose } \\
\hline & mGy/MBq & $\mathrm{rad} / \mathrm{mCi}$ & $\mathrm{mGy}^{\star}$ & rad $^{*}$ \\
\hline Early & 0.0028 & 0.010 & $0.11-0.42$ & $0.011-0.042$ \\
\hline $3 \mathrm{mo}$ & 0.0040 & 0.015 & $0.16-0.60$ & $0.016-0.060$ \\
\hline $6 \mathrm{mo}$ & 0.0050 & 0.018 & $0.20-0.75$ & $0.020-0.075$ \\
\hline $9 \mathrm{mo}$ & 0.0040 & 0.015 & $0.16-0.60$ & $0.016-0.060$ \\
\hline
\end{tabular}

*Maternal administered activity, 40-150 MBq (1.1-1.4 mCi).

Data are from Russell et al. (32). No information about possible placental crossover of this compound was available for use in estimating fetal doses.

TABLE 5

99mTc-DTPA Aerosol: Dose Estimates to the Fetus

\begin{tabular}{lllc}
\hline & & \multicolumn{2}{c}{ Fetal dose } \\
\cline { 2 - 4 } Stage of gestation & mGy/MBq & rad/mCi & mGy $^{\star}$ \\
\hline Early & 0.0058 & 0.021 & $0.12-0.23$ \\
3 mo & 0.0043 & $0.012-0.023$ & $0.086-0.17$ \\
6 mo & 0.0023 & 0.016 & $0.046-0.092$ \\
9 mo & 0.0030 & 0.0085 & $0.060-0.12$
\end{tabular}

*Maternal administered activity, 20-40 MBq (0.54-1.1 mCi).

Data are from Russell et al. (32). Information about possible placental crossover of this compound was available and was considered in estimates of fetal doses.

2. Clinical information

3. Procedure description

4. Description of findings

The report should include a description of the lung scintigraphy findings, diagnostic category, and an overall assessment of the likelihood of pulmonary embolism based on the scintigraphic findings. Terms referring to test outcome, for example, "likelihood ratio for pulmonary embolism," are preferred over terms referring to posterior probability, for example, "probability of pulmonary embolism."

5. Impression
6. Comments

The report may include an assessment of the posttest probability of pulmonary embolism based on the result of lung scintigraphy and an estimate of the prior probability of disease $(25,26)$. Many experts believe limiting reporting to 3 categories-pulmonary embolism present, pulmonary embolism absent, and nondiagnostic (intermediate likelihood ratio)facilitates communication. Some believe more accurate categorization provides more information to referring physicians (16). The outcome of patients with low-likelihood-ratio lung scans is good (27-29). 
TABLE 6

${ }^{133} \mathrm{Xe}$ : Dose Estimates to the Fetus

\begin{tabular}{lllll}
\hline & \multicolumn{3}{c}{ Fetal dose } \\
\cline { 2 - 4 } Stage of gestation & $\mathrm{mGy} / \mathrm{MBq}$ & $\mathrm{rad} / \mathrm{mCi}$ & $\mathrm{mGy}^{*}$ & $0.0050-0.019$ \\
\hline Early & 0.00025 & 0.00092 & $0.050-0.19$ & $\mathrm{rad}^{*}$ \\
$3 \mathrm{mo}$ & 0.000029 & 0.00011 & $0.0058-0.022$ & $0.00058-0.0022$ \\
$6 \mathrm{mo}$ & 0.000021 & 0.000078 & $0.0042-0.016$ & $0.00042-0.0016$ \\
$9 \mathrm{mo}$ & 0.000016 & 0.000059 & $0.0032-0.01$ & $0.00032-0.0012$
\end{tabular}

*Maternal administered activity, 200-750 MBq (5.4-20 mCi).

Data are from Russell et al. (32). No information about possible placental crossover of this compound was available for use in estimating fetal doses.

TABLE 7

$81 \mathrm{mKr}$ : Dose Estimates to the Fetus

\begin{tabular}{lcccc}
\hline & & \multicolumn{2}{c}{ Fetal dose } & \multicolumn{1}{c}{$\mathrm{rad}^{*}$} \\
\cline { 2 - 5 } Stage of gestation & $\mathrm{mGy} / \mathrm{MBq}$ & $\mathrm{rad} / \mathrm{mCi}$ & $7.2 \times 10^{-6}$ to $7.2 \times 10^{-5}$ & $7.2 \times 10^{-5}$ to $7.2 \times 10^{-6}$ \\
\hline Early & $1.8 \times 10^{-7}$ & $6.7 \times 10^{-7}$ & $7.2 \times 10^{-6}$ to $7.2 \times 10^{-5}$ & $7.2 \times 10^{-5}$ to $7.2 \times 10^{-6}$ \\
$3 \mathrm{mo}$ & $1.8 \times 10^{-7}$ & $6.7 \times 10^{-7}$ & $1.1 \times 10^{-5}$ to $1.1 \times 10^{-4}$ & $1.1 \times 10^{-6}$ to $1.1 \times 10^{-5}$ \\
$6 \mathrm{mo}$ & $2.8 \times 10^{-7}$ & $1.0 \times 10^{-6}$ & $1.4 \times 10^{-5}$ to $1.4 \times 10^{-4}$ & $1.4 \times 10^{-6}$ to $1.4 \times 10^{-5}$
\end{tabular}

${ }^{*}$ Maternal administered activity, $40-400 \mathrm{MBq}(1.1-11 \mathrm{mCi})$.

Dose estimates to the fetus were not provided by Russell et al. (32) but were estimated using kinetic data in ICRP 53. No information about possible placental crossover of this compound was available for use in estimating fetal doses.

\section{EQUIPMENT SPECIFICATION}

\section{A. Ventilation}

A disposable nebulizer is needed for ${ }^{99} \mathrm{~m}$ Tc-labeled aerosol. A xenon gas ventilation system should include capabilities for single-breath, wash-in or equilibrium, and washout phases. A xenon trap should be available for exhausted gas. An ultrafine dispersion of $99 \mathrm{mTc}$ labeled carbon produced using a commercial system is not currently available in the United States.

\section{B. Planar imaging}

Refer to the SNM Guideline for General Imaging.

\section{SPECT}

Refer to the SNM Guideline for General Imaging.

\section{SPECT/CT}

Refer to the SNM Guideline for SPECT/CT.

\section{QUALITY CONTROL AND IMPROVEMENT, SAFETY, INFECTION CONTROL, AND PATIENT EDUCATION CONCERNS}

Refer also to the SNM Guideline for General Imaging.

Radiochemical purity and particle size determination of ${ }^{99 m}$ Tc-MAA should be performed. Reconstituted MAA should be stored in a refrigerator and used before expiration. Dose reduction in pediatric imaging is always desirable, as long as image quality is maintained (13).

\section{RADIATION SAFETY IN IMAGING}

Radiation dosimetry in adults, 5-y-old children, and the fetus are presented in Tables 2-7.

Regarding the breastfeeding patient, ICRP Publication 106, Appendix D, suggests a 12-h interruption of breast feeding for subjects receiving $150 \mathrm{MBq}(4.1 \mathrm{mCi})$ of ${ }^{99 \mathrm{~m}} \mathrm{Tc}-$ MAA; it does not provide a recommendation about interruption of breastfeeding for ${ }^{99 \mathrm{~m}}$ Tc-DTPA aerosols (but suggests that no interruption is needed for ${ }^{99 \mathrm{~m}}$ Tc-DTPA intravenously administered or ${ }^{99 \mathrm{~m} T c-T e c h n e g a s ~[C y c l o m e d i c a ~ L t d .]) ; ~ t h e ~}$ authors recommend that no interruption is needed for breastfeeding patients administered ${ }^{133} \mathrm{Xe}$ or ${ }^{81 \mathrm{~m}} \mathrm{Kr}$.

\section{ACKNOWLEDGMENTS}

The Committee on SNM Guidelines consists of the following individuals: Kevin J. Donohoe, MD (Chair) (Beth Israel Deaconess Medical Center, Boston, MA); Dominique Delbeke, MD (Vanderbilt University Medical Center, Nashville, TN); Sue Abreu, MD (Sue Abreu Consulting, Nichols Hills, OK); Twyla Bartel, DO (UAMS, Little Rock, AR); Paul E. Christian, CNMT, BS, PET (Huntsman Cancer Institute, University of Utah, Salt Lake City, UT); S. James Cullom, PhD (Cardiovascular Imaging Technology, Kansas City, MO); Vasken Dilsizian, MD (University of Maryland Medical Center, Baltimore, MD); Kent Friedman, MD (NYU School of Medicine, New 
York, NY); Jay A. Harolds, MD (OUHSC-Department of Radiological Science, Edmond, OK); Aaron Jessop, MD (Vanderbilt University Medical Center, Nashville, TN); J. Anthony Parker, MD, PhD (Beth Israel Deaconess Medical Center, Boston, MA); Rebecca A. Sajdak, CNMT, FSNMTS (Loyola University Medical Center, Maywood, IL); Heiko Schoder, MD (Memorial SloanKettering Cancer Center, New York, NY); Barry L. Shulkin, MD, MBA (St. Jude Children's Research Hospital, Memphis, TN); Michael G. Stabin, PhD (Vanderbilt University, Nashville, TN); Mark Tulchinsky, MD (Milton S. Hershey Medical Center, Hershey, PA); and Jerold W. Wallis, MD (Mallinckrodt Institute of Radiology, St. Louis, MO).

\section{REFERENCES}

1. Beckles MA, Spiro S, Colis G, Rudd R. The physiologic evaluation of patients with lung cancer being considered for resectional surgery. Chest. 2003;123(suppl): 105S-114S.

2. Reilly JJ. Evidence-based preoperative evaluation of candidates for thoracotomy. Chest. 1999;116(suppl):474S-476S.

3. Win T, Tasker A, Groves A, et al. Ventilation-perfusion scintigraphy to predict postoperative pulmonary function in lung cancer patients undergoing pneumonectomy. AJR. 2006;187:1260-1265.

4. Humplik BI, Sandrock D, Aurisch R, Richter WS, Ewert R, Munz DL. Scintigraphic results in patients with lung transplants: a prospective comparative study. Nuklearmedizin. 2005;44:62-68.

5. Starobin D, Shitrit D, Steinmetz A, Fink G, Hardoff R, Kramer MR. Quantitative lung perfusion following single lung transplantation. Thorac Cardiovasc Surg. 2007;55:48-52.

6. Gates GF, Orme HW, Dore EK. Measurement of cardiac shunting with technetium-labeled albumin aggregates. J Nucl Med. 1971;12:746-749.

7. Hollett P, Wright E, Wesolowski C, Harris R. Aerosol ventilation scintigraphy in the evaluation of bronchopleural fistula: a case report and literature review. Can J Surg. 1991;34:465-467.

8. Jacobson AF, Herzog SA. Open bronchial stump post-pneumonectomy: findings on xenon-133 ventilation imaging. J Nucl Med. 1993;34:462-464.

9. Itti E, Fauroux B, Pigeot J, et al. Quantitative lung perfusion scan as a predictor of aerosol distribution heterogeneity and disease severity in children with cystic fibrosis. Nucl Med Commun. 2004;25:563-569.

10. Stanchina ML, Tantisira KG, Aquino SL, Wain JC, Ginns LC. Association of lung perfusion disparity and mortality in patients with cystic fibrosis awaiting lung transplantation. J Heart Lung Transplant. 2002;21:217-225.

11. Tunariu N, Gibbs JR, Win Z. Ventilation-perfusion scintigraphy is more sensitive than multidetector CTPA in detecting chronic thromboembolic pulmonary disease as a treatable cause of pulmonary hypertension. J Nucl Med. 2007;48:680-684.

12. Wells PS, Anderson DR, Rodger M, et al. Derivation of a simple clinical model to categorize patients probability of pulmonary embolism: increasing the models utility with the SimpliRED D-dimer. 2000. Thromb Haemost. 2000;83:416-420.

13. Gelfand MJ, Parisi M, Treves ST. Pediatric radiopharmaceutical administered doses: 2010 North American Consensus Guidelines. J Nucl Med. 2011;52:318-322.
14. Treves ST. Pediatric Nuclear Medicine. 3rd ed. New York, NY: Springer-Verlag; 2006.

15. Freeman LM, Blaufox MD. SPECT V/Q imaging of the lungs. Semin Nucl Med. 2010;40:393-394.

16. Parker JA. Improving lung scintigraphy. J Nucl Med. 2009;50:1919-1920.

17. PIOPED Investigators. Value of the ventilation/perfusion scan in acute pulmonary embolism: results of the prospective investigation of pulmonary embolism diagnosis (PIOPED). JAMA. 1990;263:2753-2759.

18. Gottschalk A, Sostman HD, Coleman RE, et al. Ventilation-perfusion scintigraphy in the PIOPED study. Part II. Evaluation of the scintigraphic criteria and interpretations. J Nucl Med. 1993;34:1119-1126.

19. Sostman HD, Coleman RE, DeLong DM, et al. Evaluation of revised criteria for ventilation-perfusion scintigraphy in patients with suspected pulmonary embolism. Radiology. 1994;193:103-107.

20. Sostman HD, Stein PD, Gottschalk A, et al. Acute pulmonary embolism: sensitivity and specificity of ventilation-perfusion scintigraphy in PIOPED II study. Radiology. 2008;246:941-946.

21. Sostman HD, Miniati M, Gottschalk A, et al. Sensitivity and specificity of perfusion scintigraphy combined with chest radiography for acute pulmonary embolism in PIOPED II. J Nucl Med. 2008;49:1741-1748.

22. Freeman LM, Krynyckyi B, Zuckier LS. Enhanced lung scan diagnosis of pulmonary embolism with the use of ancillary scintigraphic findings and clinical correlation. Semin Nucl Med. 2001;31:143-157.

23. Gutte H, Mortensen J, Jensen CV, et al. Detection of pulmonary embolism with combined ventilation-perfusion SPECT and low-dose CT: head-to-head comparison with multidetector CT angiography. J Nucl Med. 2009;50:19871992.

24. Stein PD, Freeman LM, Sostman HD, et al. SPECT in acute pulmonary embolism. J Nucl Med. 2009;50:1999-2007.

25. Wells PS, Ginsberg JS, Anderson DR, et al. Use of a clinical model for safe management of patients with suspected pulmonary embolism. Ann Intern Med. 1998;129:997-1005.

26. British Thoracic Society guidelines for the management of suspected acute pulmonary embolism. Thorax. 2003;58:470-484.

27. Lee ME, Biello DR, Kumar B, et al. "Low-probability" ventilation perfusion scintigrams: clinical outcomes in 99 patients. Radiology. 1985;156:497-500.

28. Smith R, Maher JM, Miller RI, et al. Clinical outcomes of patients with suspected pulmonary embolism and low-probability aerosol-perfusion scintigrams. Radiology. 1987;164:731-733.

29. Kahn D, Bushnell DL, Dean R, et al. Clinical outcome of patients with a "low probability" of pulmonary embolism on ventilation-perfusion lung scan. Arch Intern Med. 1989;149:377-379.

30. International Commission on Radiological Protection. ICRP publication 53, radiation dose to patients from radiopharmaceuticals. Ann ICRP. 1988;18.

31. International Commission on Radiological Protection. ICRP publication 80, radiation dose to patients from radiopharmaceuticals: addendum 2 to ICRP publication 53. Ann ICRP. 1998;28.

32. Russell JR, Stabin MG, Sparks RB, Watson EE. Radiation absorbed dose to the embryo/fetus from radiopharmaceuticals. Health Phys. 1997;73:756-769.

\section{APPROVAL}

This practice guideline (version 4.0) was approved by the Board of Directors of the SNM on July 19, 2011. Version 1.0 was approved on January 14, 1996; version 2.0 on February 7, 1999; and version 3.0 on February 7, 2004. 